- Delivering postgraduate courses to an audience of mixed experience can be difficult.

- Educational objectives and learning outcomes, based on the intended audience, need to be defined by those commissioning courses.

- Successful postgraduate education requires the participants to be prepared in an educational sense for the courses they are to attend.

\title{
Those who can, teach, but who teaches the learners to learn?
}

\author{
P. Jacobsen ${ }^{1}$
}

This article was stimulated by Mike Grace's editorial Can those who do - teach $?^{1}$ I have been an undergraduate and postgraduate teacher for over 30 years and I agreed with everything that Mike said about the difficulties of combining doing and teaching. The best doers may not make the best teachers and conversely the best teachers are not always incapable of doing, whatever some colleagues may think to the contrary!

There is now much greater emphasis in the universities on teaching the teachers, particularly following the formation of the Institute for Learning and Teaching, now the Higher Education Academy. There is also much effort devoted to providing the students with learning objectives for every session and seeking formalised feedback and appraisal of teaching.

Dental postgraduate education is now much better organised than 30 years ago. Gone (as far as I know) are the days when we could turn up at seven in the evening to give a lecture and find that no-one knew where the keys to the lecture theatre were! Postgraduate teachers are now rightly regarded as a valuable resource to be nurtured because most state-funded postgraduate education works on goodwill and understanding between the teachers, the postgraduate deans and - coming to my main theme - the audience.

${ }^{1}$ Reader in Restorative Dentistry, Cardiff University, Wales College of Medicine, Heath Park, Cardiff, CF14 4XY. Correspondence to: Dr Peter Jacobsen

Email: Jacobsenph@cardiff.ac.uk

\section{Refereed Paper}

Received 22.07.04; Accepted 23.07.04

doi: $10.1038 /$ sj.bdj.4812248

๑ British Dental Journal 2005; 198: 459-460
There was one essential part of the learning and teaching equation that was not mentioned in Mike Grace's piece and that was the role of the learner in the educational process. The formalisation of dental postgraduate education in the last 10 years or so has led to course objectives being required from the teachers and appraisal of the course required from the participants afterwards. With reference to one of Mike Grace's comments on course feedback, it is not uncommon to read after a course 'excellent and gifted teacher' from one participant, and 'arrogant and opinionated' from another. It is clear that we cannot please all the people all the time but to me this is a reflection of a big underlying problem.

The problem is that 'successful learning' depends not only on the teacher but also on the learner. In any postgraduate audience there are genuine learners who have come to be educated and others who want a quick fix - 'tell me how, don't tell me why'. A nice example comes from a recent course appraisal: 'I don't want a comparison of all the different materials, I just want to know which are the best and which I should avoid.'

Dental Protection has a view on this approach. In its last annual review it was stated: Following a postgraduate course dentists often select materials that have been endorsed by a rather evangelical speaker who has convinced them about the merits of the material. It is important that the clinician devotes time to ensuring that the properties of the material and its indications for use are fully understood.

The fact that some of the postgraduate audience are expecting 'free information' and apparently are not expecting to work things out for themselves after an educational process, suggests that there is a problem.

With the statutory requirement to attend courses now part of our culture, we are seeing people on courses who have rarely attended courses before and are new to the environment. People attending courses come with often very different expectations of the course, how they might respond and what they might do with the information imparted. Structuring a course to suit a 'mixed audience' of different expectations is a real challenge, and may not be successful if you have misjudged your audience or your brief has not been properly defined.

This latter point may be illustrated by a telephone call from a postgraduate tutor asking me "to come and do a day for us'. 
Who would be the audience? VTs and trainers. What topics are wanted and what are the objectives? Just current concepts in restorative dentistry. Please come back to me with a more clearly defined set of objectives so that I can see if I'm appropriate and give me an idea about what to say. No reply - but two weeks later the tutor's secretary contacted me with thanks for agreeing to speak. Sorry, but I'm still waiting for further information.

Mixed ability and experience in a postgraduate audience is a real challenge - we separate out the VT educational programme but one size fits all after that. Is this appropriate? Is it an acceptable use of public money to fire a blunderbuss in the general direction of a mixed audience with the expectation that the odd pellet will do some lasting damage?

For many years I made a substantial contribution to what started as an MGDS course and then was re-designated as an advanced revision course. Within the audience in the earlier years there would be a high proportion of people preparing for the examination. As a teacher, you knew where you were. You could structure your lectures to provide the information appropriate to a clearly defined objective. When the numbers of examination candidates declined and the audience included people who had just finished VT and all points beyond, the atmosphere changed. The examination candidates still needed the examination preparation but the others needed something else in a different style - a teaching dilemma!

So can the learners be better defined? Can they be better prepared for a learning process that needs to be interactive? Interaction can be daunting for some of our shyer colleagues; can the educational objectives be clearer?

For us as teachers to be successful we do not only have to fulfil the requirements mentioned earlier, but we need our postgraduates to know how to learn, reflect on what they have heard and then decide first, whether they can or want to apply what they have heard and second, how to do it in their own circumstances.

In the Bristol University Open Learning for Dentists (BUOLD) courses with which I have been associated since their inception, we addressed this problem from the beginning. We wrote a booklet that included, amongst other information, advice on how to approach the course, how to create an appropriate environment for reading the modules and writing essays - no TV or CD player, no cocktail cabinet - how to read the modules and associated papers. In short we are teaching our students how to learn.

This is all very well for a nine month distance learning course where we have a self-selecting and captive audience, but how does it apply to typical short Section 63 courses? Well, in my view, we should have the same responsibilities to ensure that the participants are prepared for what they are about to receive. I suggest that every postgraduate deanery should provide a core course on learning for every dentist in its region and restrict attendance on other courses to only those who have been through this process. In this way we might find our courses are better appreciated with better participation, and that they deliver the value for money that everyone wants.

1. Grace M. Can those who do - teach? Br Dent J 2004; 196: 375 . 